\title{
AVALIAÇÃO DO MÓDULO DE ELASTICIDADE DA ALVENARIA DA IGREJA DO ROSÁRIO, ICÓ, ATRAVÉS DO MÉTODO ULTRASSÔNICO INDIRETO
}

\author{
SOEIRO, MARCOS ANDREW \\ Professor, Mestre \\ UNIFOR/LAREB \\ Ceará; Brasil \\ marcos@duosestruturais.eng.br
}

\author{
MESQUITA, ESEQUIEL \\ Professor, $\mathrm{PhD}$ \\ UFC - Russas/LAREB \\ Ceará; Brasil \\ emesquita@ufc.br
}

\author{
ARAUJO, EMANUEL HENRIQUE \\ Aluno de Graduação \\ UFC - Russas/LAREB \\ Ceará; Brasil \\ emanuhenriqcivil@gmail.com
}

\author{
RODRIGUES, THIAGO \\ Aluno de Graduação \\ UNIFOR \\ Ceará; Brasil \\ thiagotr26@gmail.com
}

\author{
SOUSA, ISRAEL \\ Aluno de Graduação \\ UFC - Russas/LAREB \\ Ceará; Brasil \\ israelnlsousa@gmail.com
}

\author{
RODRIGUES, TALISSON \\ Aluno de Graduação \\ UFC - Russas/LAREB \\ Ceará; Brasil \\ talisson.ecivil@alu.ufc.br
}

\section{RESUMO}

As construções históricas possuem uma grande importância em nossa sociedade, portanto, é relevante estudarmos como preservá-las, pois muitas destas construções são datadas de séculos. Para garantir a segurança estrutural destas construções, a obtenção das propriedades dos materias que a compõem é de suma importância, porém, difícil, devido a complexidade dos sistemas estruturais adotados, como a alvenaria de tijolos maciços. Sendo assim, os ensaios não destrutivos (END) surgem como uma excelente forma de se extrair informações acerca destas propriedades sem provocar danos à estrutura, sendo o ensaio de velocidade de pulso ultrassônico um dos mais utilizados atualmente. Neste trabalho, foram realizados ensaios ultrassônicos pelo método indireto em vários painéis de alvenaria da Igreja do Rosário, situada em Icó, Ceará, Brasil, datada de 1828, com intuito de se obter através de formulações já conhecidas no meio acadêmico, o módulo de elasticidade, e por fim caracterizar o material desta construção, auxiliando em futuros trabalhos de intervenções que podem surgir.

Palavras-chave: ultrassom, painel de alvenaria, caracterização de material, método indireto.

\section{ABSTRACT}

Historical buildings are of great importance in our society, so it is important to study how to preserve them, because many of these buildings dated from centuries. To guarantee the structural safety of these constructions, obtaining the properties of the materials that compose it is extremely important, but difficult due to the complexity of the adopted structural systems, such as solid brick masonry. Thus, non-destructive testing (NDT) is an excellent way to extract information about these properties without causing damage to the structure, being the ultrasonic pulse speed test one of the most used today. In this work, ultrasonic tests were performed by the indirect method on various masonry panels of the Church of Rosario, located in Icó, Ceará, Brazil, dating from 1828, in order to obtain through formulations already known in academia, the modulus of elasticity, and finally characterize the material of this construction, assisting in future work of interventions that may arise.

Keywords: ultrasound, masonry panel, characterization of material, indirect method.

\section{INTRODUÇÃO}

Visando a conservação dos patrimônios históricos na atualidade, surge a necessidade da utilização de ensaios que caracterizem, de alguma forma, a estrutura da edificação, pois, com o passar dos anos, estas estruturas podem se tornar vulneráveis devido à alguns fatores como: intempéries ambientais ou falta de manutenção adequada.

Por se tratar de construções muito antigas, no momento da realização destes ensaios, tem-se sempre o cuidado de diminuir ao máximo o dano na edificação ou até mesmo em não gerar dano algum. Diante disso, surgiram na construção civil, muitos testes denominados de "ensaios não destrutivos" (END) que se destacam por serem uma ótima opção para avaliar a integridade das edificações históricas causando pouco dano e em alguns casos chegando a dano zero, e por sua 
natureza não destrutiva, permite o reensaio no mesmo local, o que facilita o acompanhamento do estado de conservação da estrutura com o passar do tempo (SILVA, 2019).

Segundo (ALVES, A. e colab., 2016), os ensaios não destrutivos têm hoje um papel de grande destaque no âmbito da construção civil, sendo suas principais vantagens, nomeadamente: custo reduzido, facilidade de aplicação e o fato de causar pouca avaria à estrutura.

No meio da construção civil, estes métodos podem ser usados tanto para avaliação de estruturas novas como também para edificações mais antigas. Para estruturas recentes, as principais aplicações são relativas ao controle de qualidade ou a resolução de dúvidas sobre a qualidade dos materiais ou a construção. Em estruturas mais antigas, os END geralmente são relacionados a uma avaliação da integridade ou adequação estrutural (INTERNATIONAL ATOMIC ENERGY AGENCY, 2002).

De um modo geral, existem duas classes de ensaios não destrutivos para aplicação em estruturas. A primeira que consiste em métodos usados para estimar a resistência do material, tais como o ensaio de dureza superficial (esclerometria), resistência à penetração, ensaios de arrancamento e método da maturidade. A segunda classe inclui os métodos que medem outras características e defeitos internos da estrutura por meio de propagação de ondas e termografia infravermelha. Além desses, existem outros que fornecem informações sobre à armadura em estruturas de concreto armado, como a localização das barras de aço, seu diâmetro e o potencial de corrosão (MALHOTRA e CARINO, 2003).

De acordo com (BINDA e colab., 2000), para se ter um grau de confiabilidade alto nos resultados dos ensaios, alguns parâmetros da estrutura precisam ser conhecidos, porém, estes parâmetros a serem verificados nos ensaios variam de acordo com o tipo de material utilizado, como por exemplo, em alvenaria de tijolo, os principais fatores são nomeadamente: a sua geometria, as características da sua textura, se feita por fiadas únicas ou múltiplas, o tipo de conexão entre as fiadas, se as articulações estão vazias ou preenchidas com argamassa, as características físicas, químicas e mecânicas dos componentes e as características da alvenaria como um material compósito.

Dentre os END mais utilizados, destaca-se o ensaio de velocidade de pulso ultrassônico, por permitir aplicação nas mais diversas situações. Esse teste consiste na medição do tempo que uma onda mecânica demora para atravessar certo material. O método de velocidade de pulso ultrassônico é útil em alvenarias para sua qualificação através da morfologia da secção de parede; para detectar a presença de espaços vazios e falhas e para encontrar padrões de fissura e danos. Assim, de forma geral, este método avalia propriedades mecânicas de alvenarias (ALVES, A. e colab., 2016).

No presente trabalho, a técnica de determinação da velocidade ultrassônica foi aplicada nas alvenarias de tijolo maciço da Igreja de Nossa Senhora do Rosário, uma edificação de interesse histórico localizada no município de Icó, no estado do Ceará, de modo a determinar as suas características mecânicas, tendo como principal objetivo o cálculo do módulo de elasticidade global da edificação.

\section{HISTÓRICO E CARACTERÍSTICAS ARQUITETÔNICAS DA EDIFICAÇÃO ANALISADA}

A Igreja de Nossa Senhora do Rosário (Figura 1) foi construída em 1828, na parte norte da vila pela sociedade colonial; como em muitas outras cidades do país, revela em sua posição distanciada da parte principal da urbe à época, no fim das ruas Dr. Inácio Dias e General Pirangibe, a exclusão social das pessoas de classes menos favorecidas, que eram considerados desprezíveis e tratados como simples objetos, em relação aos mais ricos. Na época seria uma grande falta de respeito o branco andar ou participar de algum evento com um negro (LIMA, 1995).

Fica notória a importância histórica e religiosa desse templo para os negros, que tinham a Virgem do Rosário como sua grande protetora. $\mathrm{Na}$ época, o local era considerado o refúgio dos homens pardos, que de tanto sofrer com a discriminação racial, que nesta igreja e somente nela, que os negros escravos podiam assistir seus atos religiosos. $\mathrm{O}$ preconceito era tão predominante que a igreja já chegou a ser chamada de Igreja dos Escravos, posteriormente Igreja de Nossa Senhora do Rosário dos Homens Pardos (VIANA, 2011).

Com relação a arquitetura, o templo possui três naves e na nave central está o altar principal, que guarda imagens como a de Santa Luzia, São Benedito e Nossa Senhora da Apresentação, além da imagem principal de N. Sra. Do Rosário. A Igreja também possui um cruzeiro à sua frente e sua fachada é composta por duas torres, uma de cada lado, sendo a sineira à sua esquerda, medindo cerca de $24 \mathrm{~m}$ de altura, base quadrada e terminação piramidal, também quadrada. 
As três portas principais, correspondentes à nave central, são almofadadas e as superiores são guarnecidas por balcões de ferro e os vãos das portas principais possuem arco. Os frontões das áreas correspondentes às circulações lateral direita e esquerda são triangulares, com cimalhas encurvadas e alteadas, volutas e coruchéus diversos (FEITOSA, 2018).

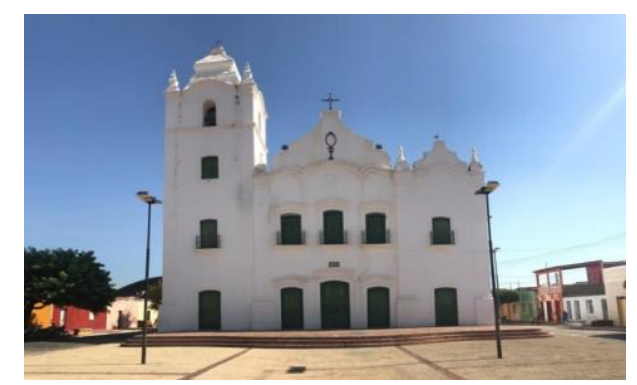

Figura 1: Fachada frontal da Igreja

A Igreja possui $30,89 \mathrm{~m}$ de comprimento e $17,24 \mathrm{~m}$ de largura, resultando em uma área de aproximadamente $533 \mathrm{~m}^{2}$ e está dividida em 10 ambientes. A estrutura da Igreja é composta por alvenaria de tijolos maciços com espessuras variando entre $56 \mathrm{~cm}$ e $100 \mathrm{~cm}$ em todo o corpo da Igreja, e $218 \mathrm{~cm}$ na base da torre sineira, e foi construída utilizando-se técnicas construtivas locais com os materiais disponíveis na época, sendo o ajuste comum, o tipo de amarração utilizado.

Considerando que a edificação possui 190 anos de história, hoje podemos considerar que a Igreja Nossa Senhora do Rosário está em ótimo estado de conservação o que diz respeito ao aspecto físico, inclusive continua sendo utilizada para celebrações eucarísticas, o que nos faz perceber a importância do processo de tombamento de um bem histórico no que diz respeito à preservação da memória e cultura de toda uma comunidade.

\section{METODOLOGIA UTILIZADA}

O ensaio utilizado para a monitorização estrutural da Igreja Nossa Senhora do Rosário foi o de velocidade de pulso ultrassônico, onde utilizamos o aparelho PUNDIT P1 - 200, com transdutores de 54 KHz, demonstrado na Figura 2.

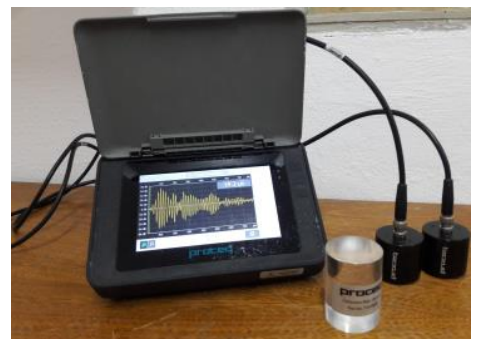

Figura 2: Equipamento utilizado

O equipamento possui dois transdutores, um transmissor e um receptor, que são responsáveis por transmitir e receber as ondas mecânicas que irão percorrer através da estrutura de alvenaria e também transformar essas ondas em estímulos elétricos e vice-versa. Sendo assim, o posicionamento destes transdutores, influencia em alguns parâmetros do ensaio, como o tipo de onda a ser analisada.

Segundo a NBR 8802 (ABNT, 2019), existem três tipos de transmissão de pulso ultrassônico (Figura 3), que estão relacionados ao posicionamento dos transdutores, que são nomeadamente: direta, semidireta e indireta.

Dos arranjos apresentados na Figura 3, o ideal é o de transmissão direta pois é o que possibilita que as ondas sejam recebidas com mais intensidade, porém quando não houver a possibilidade do uso deste, como o caso especifíco de nossa edificação, poderá se proceder com posicionamento dos transdutores de forma indireta com a devida atenção com relação à distância entre os transdutores. A transmissão indireta é executada para que a alvenaria seja estudada como um sistema (argamassa + tijolo), avaliando sua complexidade e heterogeneidade, diferente do que acontece na direta, pois a análise seria exclusivamente tijolo ou argamassa. 

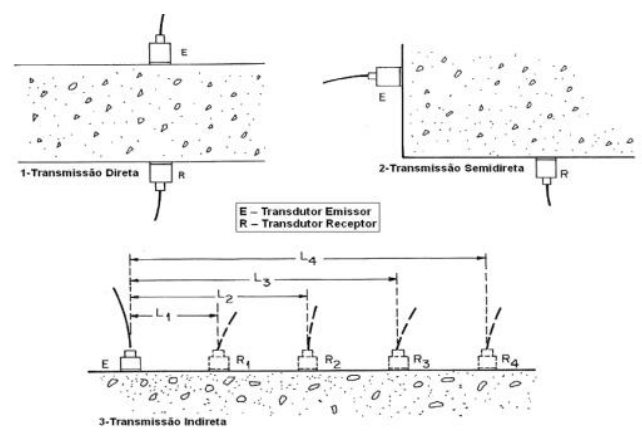

Figura 3: Tipos de transmissão NBR 8802 (ABNT, 2019), adaptado

Os critérios utilizados para determinar as localidades dos painéis foram as alvenarias que visualmente aparentassem ter características diferentes das demais, por ter sido usado materiais diferentes ou por método executivo, ou seja, o que diferenciasse das outras alvenarias. Outro critério que foi levado em consideração foi a questão de a alvenaria não ter nenhuma outra estrutura no interior da igreja que ficasse perpendicular a analisada, pois poderia nos gerar resultados não confiáveis.

Deste modo, os elementos analisados foram as fachadas laterais esquerda e direita (Figura 4), relativos a um observador posicionado nos fundos da Igreja. A quantidade de quadrantes por painél depende do tamanho da parede a ser analisada, porém todos os painés possuem no 3 quadrantes na vertical, com cotas $\mathrm{Y}$ (altura) do centro do quadrante de $1,15 \mathrm{~m}$, $1,65 \mathrm{~m}$ e $2,15 \mathrm{~m}$, já na direção horizontal, de acordo com o comprimento do painél, a cada $0,5 \mathrm{~m}$ se selecionam mais 3 quadrantes.

Sendo assim, na fachada esquerda foram selecionados dois painéis, o P2 com 15 quadrantes e o P3 com 9 quadrantes, enquanto na fachada direita foram selecionados três painéis, o P2 com 9 quadrantes e o P4 e P5 com 3 quadrantes cada.
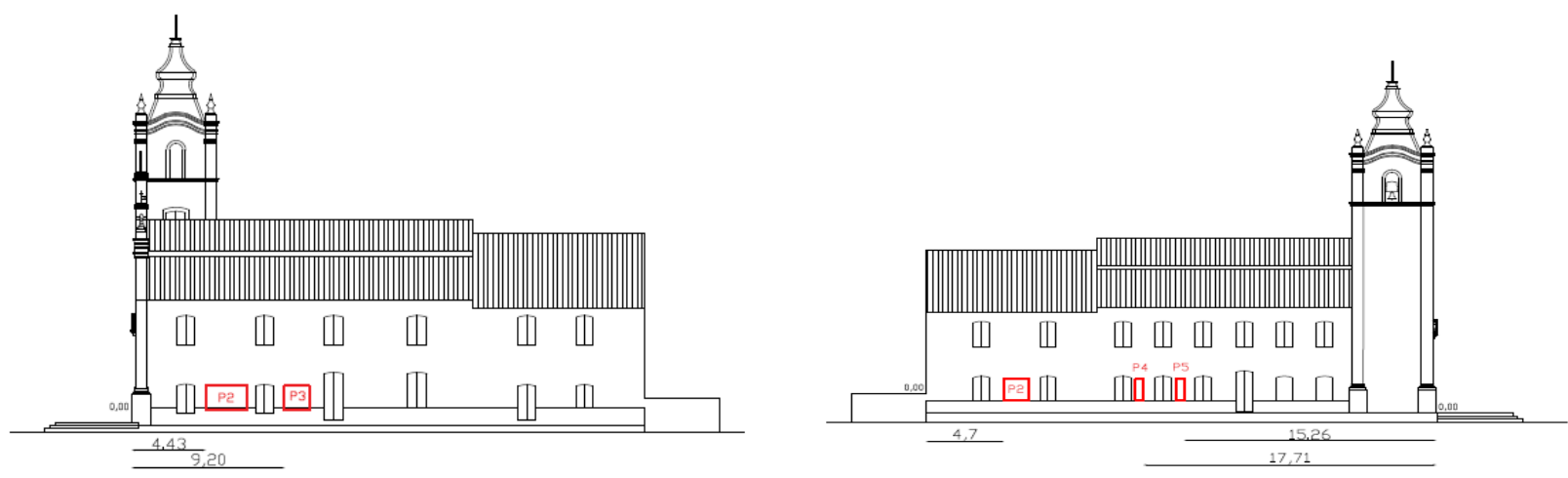

Figura 4: Fachadas esquerda e direita, respectivamente

Em relação à distância entre os trandutores, os mesmos obedeceram a NBR 8802 (ABNT, 2019), da seguinte maneira: fixou-se o transdutor transmissor em um determinado ponto fixo e a uma distância de $20 \mathrm{~cm}$ do transmissor, posicionouse o transdutor receptor na primeira posição de recepção (R1). Executou-se o envio da onda pela alvenaria e então anotou-se o tempo de propagação (que é o tempo necessário para a onda ir de um transdutor a outro). Então moveu-se, apenas, o transdutor receptor por uma distância de $5 \mathrm{~cm}$ para o ponto de recepção 2 (R2), de modo que esse ponto permaneceu em linha reta em relação ao R1. A onda foi novamente enviada e os dados registrados para o segundo ponto de recepção. Isso foi realizado 5 vezes da mesma maneira, coletando assim 5 dados para cada quadrante (Figura 5).

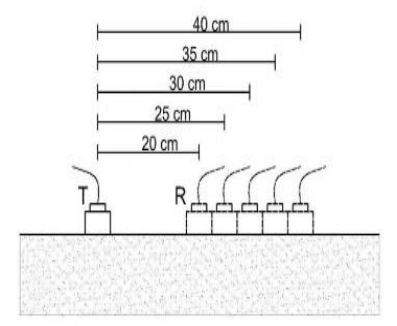

Figura 5: Distâncias entre os trandutores para um quadrante de painél (ALVES, André Luiz Santos, 2017) 


\section{RESULTADOS}

Após o término dos ensaios, foram obtidos os tempos de propagação da onda, em $\mu$ s, em cada um dos cinco pontos de cada quadrante de cada painél, totalizando assim, 195 medições. Como sabemos a distância exata entre os trandutores transmissor e receptor, conseguimos estimar os valores das velocidades ultrassônicas de cada quadrante. Os resultados obtidos podem ser vistos nos gráficos da Figura 6, onde temos no eixo x de cada gráfico as cotas $\mathrm{X}$ dos eixos de cada quadrante do pianél, de acordo com a origem mostrada na Figura 4, e temos que cada conjunto de pontos representa uma cota $\mathrm{Y}$ do eixo de cada quadrante.
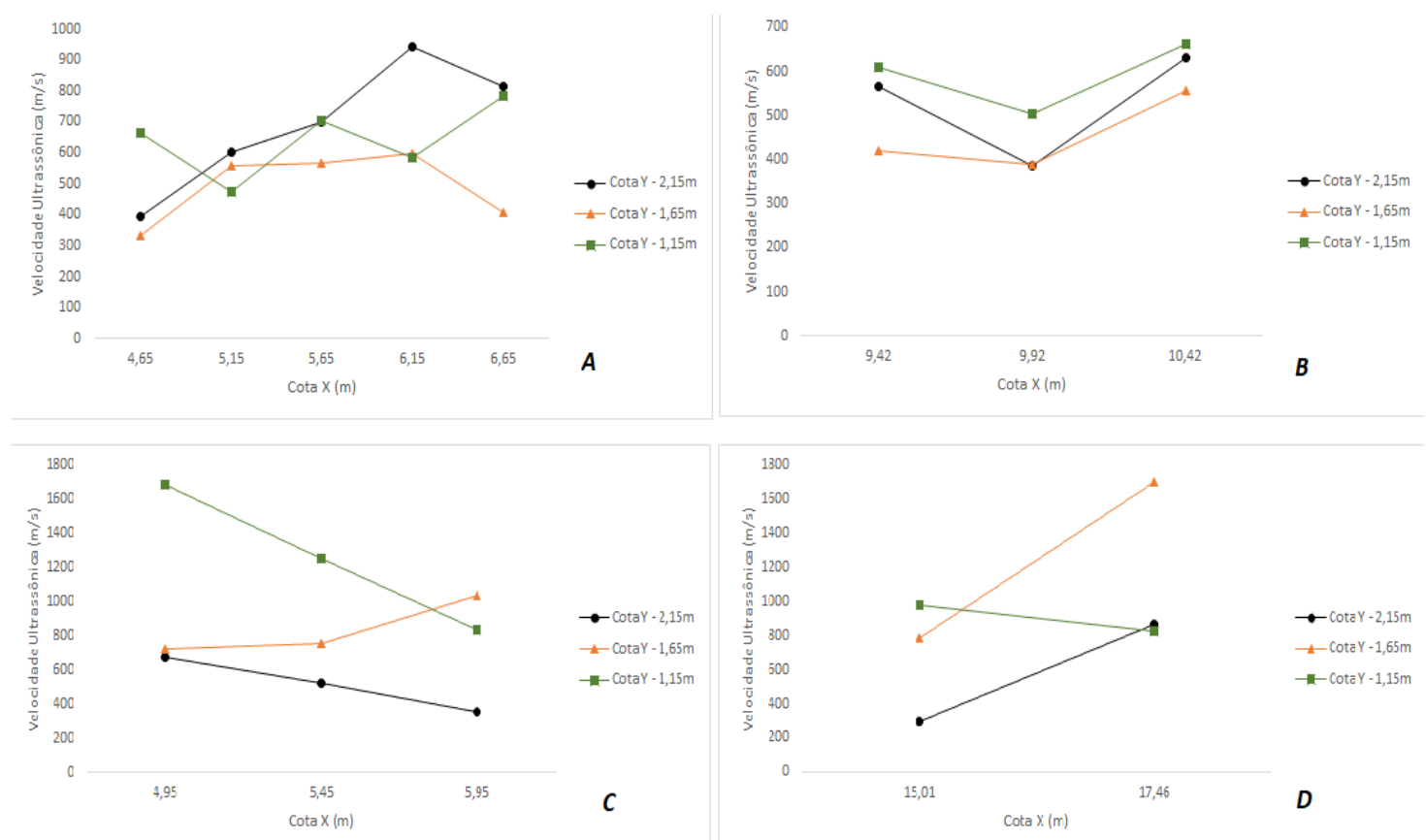

Figura 6: Velocidades ultrassônicas - (A) P2 da fachada esquerda, (B) P3 da fachda esquerda, (C) P2 da fachada direita e (D) P4 e P5 da fachada direita

A partir destes gráficos, podemos estimar as velocidades médias de cada painél, que no caso foram de $608,08 \mathrm{~m} / \mathrm{s}$ e $524,74 \mathrm{~m} / \mathrm{s}$ para o P2 e P3 da fachada esquerda, respectivamente, e de $868,56 \mathrm{~m} / \mathrm{s}, 1128,39 \mathrm{~m} / \mathrm{s}$ e $684,61 \mathrm{~m} / \mathrm{s}$ para o P2, P4 e P5 da fachada direita, respectivamente.

Todas as velocidades ultrassônicas foram agrupadas de modo a plotar a curva gaussiana na Figura 7. Através desse gráfico é possível ver a dispersão dos resultados obtidos, onde a média das velocidades ultrassônicas foi de 694,87 m/s.

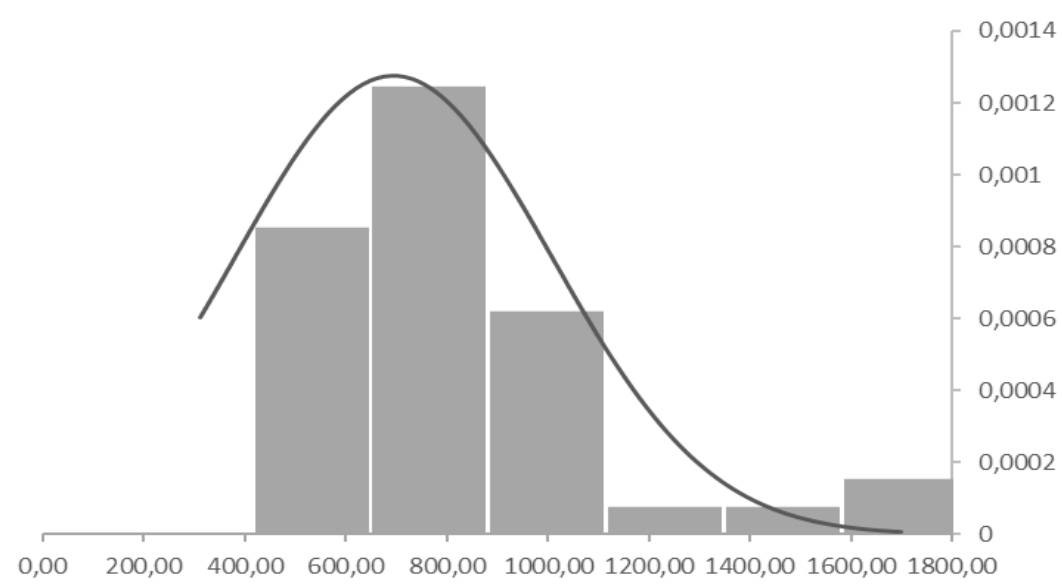

Figura 7: Curva de distribuição normal das velocidades ultrassônicas $(\mathrm{m} / \mathrm{s})$ 
O módulo de elasticidade global do material pode ser obtido através de uma equação (1) que o relaciona com as velocidades de pulso ultrassônico.

$$
V_{R}=\frac{0,87+1,12 v}{1+v} * \sqrt{\frac{E}{\rho} * \frac{1}{2(1+v)}}
$$

A equação (1) utiliza a velocidade das ondas $\mathrm{R}\left(V_{R}\right)$ para estimar o módulo de elasticidade, estas ondas $\mathrm{R}$ são acessadas pela transmissão indireta de pulsos, pois este tipo de onda se difunde ao longo da superfície de impacto, diferentemente das ondas P, que se propagam ao longo da direção de impacto, sendo melhores acessadas pela transmissão direta de ondas (ALVES, A. e colab., 2016).

As propriedades mecânicas obtidas usando esta equação são chamadas dinâmicas, porque elas são baseadas em pequenas deformações e em taxas de carregamento rápido; seus valores são frequentemente mais elevados do que as estáticas.

Podemos observar, que há a necessidade de conhecermos outros dois parâmetros do material, o coeficiente de poisson (v) e o peso específico ( $\rho$ ). O coeficiente de poisson foi o mesmo adotado por (BRANDÃO, 2016) e (DELGADO, 2013) nos seus trabalhos, no valor de 0.2 , já o peso específico foi adotado da NTC 2008 (MINISTERO DELLE INFRASTRUTTURE, 2008), no valor de $1800 \mathrm{~kg} / \mathrm{m}^{3}$.

Sendo assim, foi calculado através da equação (1), todos os valores de módulo de elasticidades, e estes foram plotados no gráfico da Figura 8.

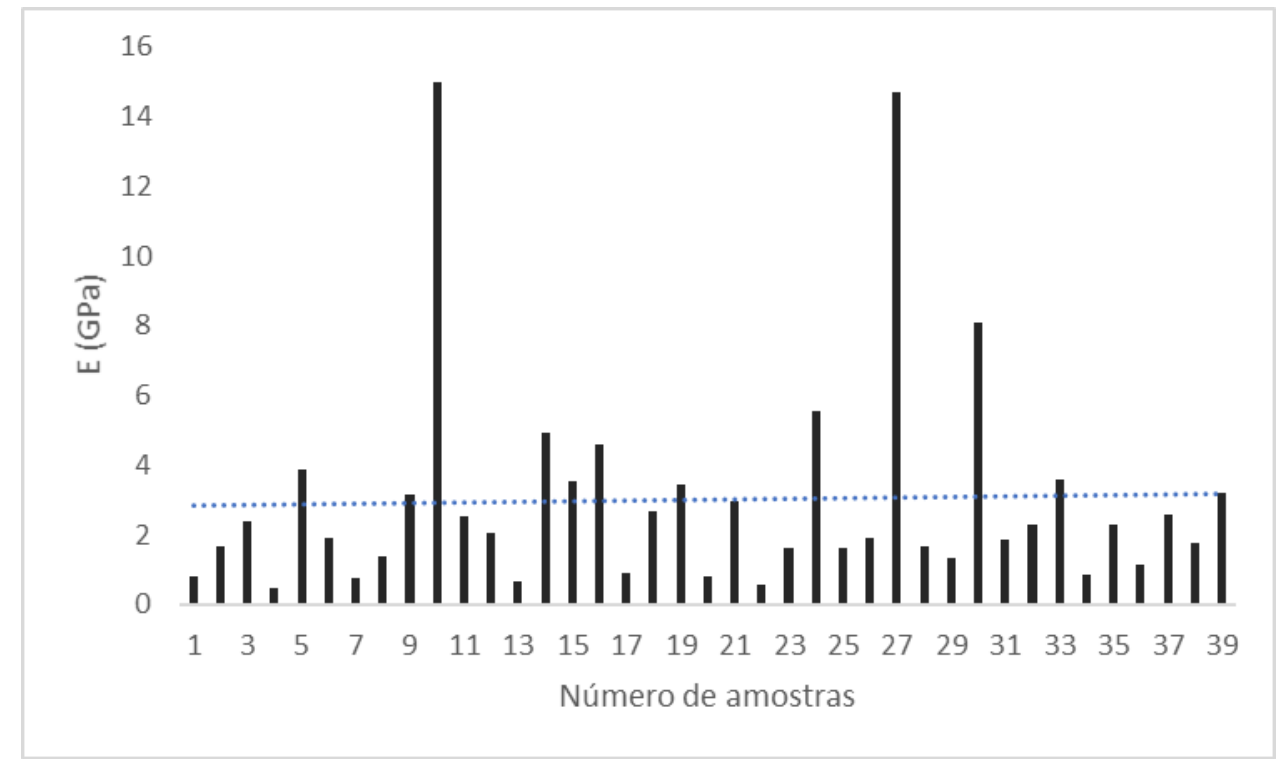

Figura 8: Módulo de elasticidade calculado

A média de todos os dados obtidos é de 3,0GPa, valor este que será, pela presente análise, considerado como o módulo de elasticidade global da edificação.

\section{CONSIDERAÇÕES FINAIS}

O ensaio de velocidade de pulso ultrassônico foi aplicado em alvenarias de tijolo cerâmico em vários pontos de uma edificação de interesse histórico. Estas análises foram feitas em pontos estratégicos das duas fachadas laterais da edificação.

As médias das velocidades ultrassônicas de cada painel individualmente foram próximas da média geral $(694,87 \mathrm{~m} / \mathrm{s})$, difererindo em no máximo, $175 \mathrm{~m} / \mathrm{s}$ para os casos dos painéis 2 e 3 da fachada esquerda e dos painéis 3 e 5 da fachada direita. No entanto o painel 4 da fachada direita ficou com uma velocidade média $(1128,39 \mathrm{~m} / \mathrm{s}), 2$ vezes acima da média geral. 
O módulo de elasticidade global encontrado da edficação foi de 3,0 GPa. Este valor mostra-se bastante razoável quando comparado aos valores relativos a alvenarias de tijolo cerâmico (calculados pelo mesmo método) encontrados em (ALVES, André e colab., 2016), e em outros trabalhos (não calculados pelo mesmo método), encontrados em (FERNANDES, 2006) e (BINDA e colab., 1993).

\section{REFERÊNCIAS}

ABNT. NBR 8802 - Concreto endurecido - Determinação da velocidade de propagação de onda ultrassônica. Associação Brasileira de Normas Técnicas, p. 15, 2019.

ALVES, A. e colab. Estimativa do módulo de elasticidade global de uma edificação histórica de alvenaria de tijolos maciços pelo método ultrassônico. Anais do Congreso Brasileiro de Patologia das Construções - CBPAT 2016, n. April, 2016.

ALVES, André e colab. Estimativa do módulo de elasticidade global de uma edificação histórica de alvenaria de tijolos maciços pelo método ultrassônico. n. April, 2016.

ALVES, André Luiz Santos. Proposição de um método de caracterização de alvenarias de edificações históricas por meio de avaliação ultrassônica. 2017. 1-89 f. Universidade Estadual Vale do Acaraú - UVA, 2017.

BINDA, L. e SAISI, A. e TIRABOSCHI, C. Investigation procedures for the diagnosis of historic masonries. Construction and Building Materials, v. 14, n. 4, p. 199-233, 2000.

BINDA, L e FOLLI, R Tongini e ROBERTI, G Mirabella. Survey and investigation for the diagnosis of damaged masonry stuctures: the "torrazzo" of Cremona. 1993, [S.1: s.n.], 1993. p. 1-10.

BRANDÃO, F. Anais do Congresso Brasileiro de Patologia das Construções - CBPAT caracterização dinâmica de um edifício histórico do século XIX Anais do Congresso Brasileiro de Patologia das Construções - CBPAT. n. April, p. 1-12, 2016.

DELGADO, Joana Louro. Avaliação sísmica de um edifício crítico em alvenaria E. 2013. 201 f. Instituto Técnico de Lisboa, 2013.

FEITOSA, Eduardo Ricarte. Análise computacional de uma edificação histórica - estudo de caso igreja nossa senhora do rosário - icó. 2018. 78 f. Universidade de Fortaleza, 2018.

FERNANDES, Francisco Manuel Carvalho Pinto. Evaluation of two novel NDT techniques: microdrilling of clay bricks and Ground Penetrating Radar in masonry. Universidade do Minho, 2006.

INTERNATIONAL ATOMIC ENERGY AGENCY. Guidebook on non-destructive testing of concrete structures. Industrial Applications and Chemistry Section, IAEA. [S.l: s.n.], 2002. Disponível em: <http://200.10.161.33/cirsoc/pdf/ensayos/tcs-17_web.pdf>.

LIMA, Miguel Porfírio De. Icó em fatos e memórias. . [S.1: s.n.], 1995.

MALHOTRA, V. M. e CARINO, N. J. Handbook on nondestructive testing of concrete, second edition. [S.l: s.n.], 2003.

MINISTERO DELLE INFRASTRUTTURE. NTC 2008-Decreto Ministeriale 14/1/2008. 2008. Disponível em: $<$ http://www.gazzettaufficiale.it/>.

SILVA, Thiago Rodrigues Pires Da. Aplicação de um método não destrutivo no patrimônio histórico - igreja nossa senhora do rosário - icó-ce. 2019. 1-67 f. Universidade de Fortaleza - UNIFOR, 2019.

VIANA, Francirton Josino. Icó: seu patrimônio, conhecer e preservar. 2011. Universidade Estadual da Paraíba, 2011. 